A. А. Елезова, E. А. Ботоева. Сравнительный анализ причин задержки внутриутробного развития плода

Научная статья

УДК 618.4

DOI: $10.18101 / 2306-1995-2021-2-29-39$

\title{
СРАВНИТЕЛЬНЫЙ АНАЛИЗ ПРИЧИН ЗАДЕРЖКИ ВНУТРИУТРОБНОГО РАЗВИТИЯ ПЛОДА
}

\author{
(C) Елезова Анна Александровна \\ врач-ординатор, \\ Бурятский государственный университет имени Доржи Банзарова \\ Россия, 670002, г. Улан-Удэ, ул. Октябрьская, 36а \\ elenabotoeva@list.ru

\section{(C) Ботоева Елена Аполлоновна} \\ кандидат медицинских наук, доцент, \\ Бурятский государственный университет имени Доржи Банзарова \\ Россия, 670002, г. Улан-Удэ, ул. Октябрьская, 36а \\ elenabotoeva@list.ru
}

Аннотация. Нарушения в периоде внутриутробного развития плода обусловливают большую долю мертворождений, а также оказывают влияние на уровень неонатальной и детской смертности, ведут к долгосрочным негативным последствиям для последующего роста, развития и здоровья детей. По данным экспертов ВОЗ, среди отдаленных последствий неадекватного питания на ранних этапах развития ребенка отмечается повышение риска заболеваний и смерти от них в любом периоде жизни. В связи с этим категория маловесных к гестационному возрасту детей заслуживает особого внимания со стороны врачей-неонатологов, педиатров, нутрициологов.

Задержка роста плода может привести к целому спектру перинатальных осложнений, включая внутриутробную гибель плода, асфиксию, аспирацию околоплодных вод, содержащих меконий, повышение частоты операций кесарева сечения.

Внедрение в ежедневную клиническую практику современных алгоритмов прогнозирования, методов эффективной профилактики, унифицированных критериев диагностики и принципов ведения случаев задержки роста плода, базирующихся на результатах исследований с высоким уровнем достоверности доказательств, будет являться базой для значительного снижения уровня перинатальной заболеваемости и смертности. Задержка роста плода является причиной каждого третьего случая антенатальной гибели.

В данной работе была предпринята попытка оценить этиологию задержки роста плода, выделив рекомендуемые в литературе основные группы факторов риска.

Ключевые слова: задержка роста плода, перинатальные осложнения, внутриутробная гибель плода, этиология, маловесные к дестационному периоду дети.

\section{Для цитирования}

Елезова А. А., Ботоева Е. А. Сравнительный анализ причин задержки внутриутробного развития плода // Вестник Бурятского государственного университета. Медицина и фармация. 2021. № 2. С. 29-39.

Актуальность. Задержка роста плода (ЗРП) как один из «больших акушерских синдромов» является патофизиологическим состоянием, многократно увеличива- 
ющим риски перинатальной смертности при данной и даже при последующих беременностях у матери. ЗРП, обусловленная нарушением функции плаценты, является причиной каждого третьего случая антенатальной гибели, общее число случаев которой в мире достигает 2,4-3,0 млн в год и не имеет значимой тенденции к снижению [1].

Частота ЗВУР в популяции весьма вариабельна и зависит от ряда причин. Так, у практически здоровых беременных СЗРП плода регистрируют в 3-5\% случаев, при отягощенном акушерско-гинекологическом диагнозе и осложненной беременности - в 10-25\% [2]. По данным ВОЗ, число новорожденных с задержкой развития колеблется от $31,1 \%$ в Центральной Азии до $6,5 \%$ в развитых странах Европы [3].

Частота ЗВУР по Республике Бурятия за 2019-2020 гг.

\begin{tabular}{|l|l|l|l|l|l|}
\hline Год & РПЦ & $\%$ & ГПЦ & $\%$ & Итого \\
\hline 2019 & 338 & 6,3 & 121 & 4,95 & $459-11,25 \%$ \\
\hline 2020 & 410 & 7,2 & 157 & 6,8 & $567-14 \%$ \\
\hline
\end{tabular}

Целью данной работы является изучение особенностей течения беременности у матерей, родивших детей с задержкой внутриутробного развития плода.

Задачи

1. Выбор основных факторов риска возникновения СЗРП на основе литературного обзора.

2. Сбор и сравнительный анализ данных пациенток с диагнозом СЗРП.

3. Выявление основных ошибок в тактике ведения беременности и разработка предложений по прогнозированию случаев СЗРП и оптимизации тактики ведения.

Материалы и методы.

В данной работе представлен анализ 31 случая среди беременных с СЗРП различной степени тяжести. Использованы индивидуальные карты беременных на базе женской консультации Городской поликлиники № 1 за 2020 г. Согласно журналу родов, случаев ЗРП за 2020 г. было 40 , из них 31 карту удалось анализировать.

За конечные точки оценивания были взяты основные факторы риска возникновения СЗРП во время беременности (возраст беременной, паритет, наличие отягощенного акушерского анамнеза (ОАА), наличие профессиональных вредностей, вредных привычек; ИМТ, наличие гинекологических заболеваний, осложнения беременности, экстрагенитальная патология, плацентарные нарушения, многоплодная беременность, инфекционные и воспалительные заболевания. Также оценивалось обследование беременных в соответствии с приказом 572н и протоколом «Нормальная беременность» 2020 г.

Обработка данных проведена с использованием универсальных программ Мicrosoft Excel 2007.

Результаты исследования

Задержка внутриутробного развития плода полиэтиологична. Для корректного формирования группы высокого риска по развититю ЗРП необходима тщательная оценка факторов риска развития нарушений функционирования маточно-плацентарной системы: материнских и плацентарных. 

плода

В первую очередь, при анализе карт беременных оценивались социально-бытовые факторы риска (возраст менее 17 и более 35 лет, профессиональные вредности (работа, связанная с длительным стоянием или излишней физической нагрузкой, работы в ночное время), вредные привычки, ИМТ менее 20 кг/м²).

По данным факторам распределение беременных осуществилось следующим образом (табл. 1).

Таблий 1

Факторы риска возникновения ЗРП, \%

\begin{tabular}{|c|c|c|c|c|c|c|c|c|c|c|c|c|c|c|}
\hline \multicolumn{2}{|c|}{ 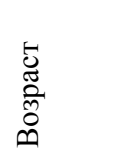 } & \multicolumn{3}{|c|}{ 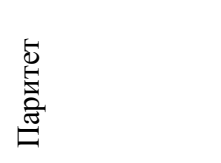 } & \multirow[t]{2}{*}{ 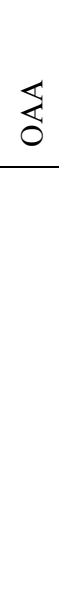 } & \multicolumn{2}{|c|}{ 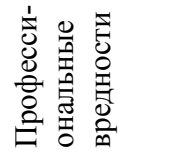 } & \multicolumn{2}{|l|}{ 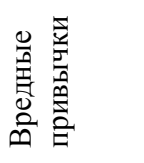 } & \multicolumn{5}{|c|}{$\sum_{j}$} \\
\hline 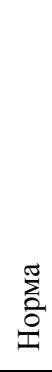 & 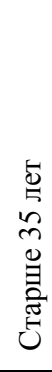 & 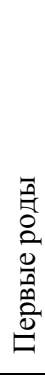 & 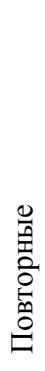 & 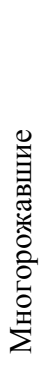 & & $\begin{array}{l}\hat{E} \\
\text { 苫 }\end{array}$ & 氞 & $\begin{array}{l}\hat{j} \\
\text { 至 }\end{array}$ & $\stackrel{5}{\underline{T}}$ & 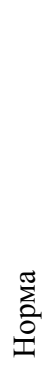 & 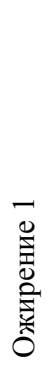 & 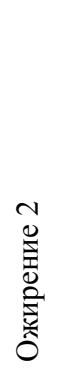 & 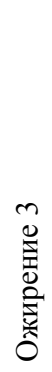 & 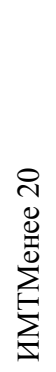 \\
\hline 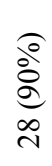 & $\begin{array}{l}0 \\
\dot{0} \\
0 \\
0 \\
0\end{array}$ & $\begin{array}{l}\frac{\partial}{2} \\
\frac{0}{0} \\
\frac{0}{ \pm}\end{array}$ & 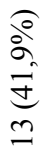 & 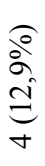 & 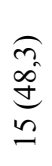 & $\begin{array}{l}\text { ô } \\
\text { in } \\
\text { ḋ } \\
\text { r }\end{array}$ & 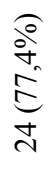 & $=\frac{8}{ \pm} \frac{8}{5}$ & 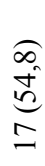 & r & $N$ & - & - & $\begin{array}{l}\text { त̂ } \\
\text { हु } \\
0 \\
0\end{array}$ \\
\hline
\end{tabular}

Стоит указать, что в ОАА упоминание о СЗРП в анамнезе было лишь у одной женщины. Возрастная категория была представлена женщинами репродуктивного возраста, большинство из которых были первородящими. Половина женщин имели ОАА, из них 5 женщин были с рубцом на матке. Профессиональные вредности: 3 женщины на ночной работе, 11 домохозяек, остальные женщины не входили в группу риска по роду деятельности. Хроническая никотиновая интоксикация была у 14 женщин, у одной указана алкогольная зависимость.

Большинство женщин имело низкую массу тела (ИМТ менее 20 кг $/ \mathrm{M}^{2}$ ). Самый

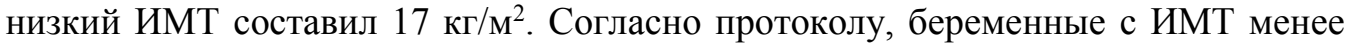
20 кг/м² составляют группу высокого риска ЗРП и пациентке должны быть даны рекомендации по прибавке массы тела.

Постановка на учёт: до 12 недель - 24 женщины и 7 женщин — во втором триместре.

Соматические факторы риска (хронические специфические и неспецифические инфекции, эктрагенитальные заболевания, гинекологические заболевания). 
По данным факторам распределение беременных осуществилось следующим образом: у шести женщин из 31 выявлена гинекологическая патология. Зачастую при сборе анамнеза указывается неполная информация, подробные сведения о перенесенных заболеваниях, проведенном лечении отсутствуют.

Среди инфекционных болезней из специфических инфекций был выявлен только трихомониаз у двух женщин, непролеченный ввиду невыполнения женщинами рекомендаций, вирусный гепатит у двух женщин, носительство ЦМВИ у одной, вагиниты, ВВК у шести женщин. Инфекционные процессы МВС у четырех женщин включали бактериурию, хронический пиелонефрит и микроэритроцитурию.

Экстрагенитальная патология чаще была представлена ГБ (3), перенесенным ОРВИ во время беременности (3), у двух женщин была перенесена НКИ в легкой форме, у двух заболевания щитовидной железы, представленные хроническим тиреоидитом и манифестным тиреотоксикозом, у одной женщины СД 1-го типа в декомпенсированной форме, приведший к двухкратной госпитализации в РЭЦ на 11 недель и 19 недель, далее в 35 недель ХФПН, НМПК одной Б. У одной женщины была СКВ, активность 1, суставной синдром, ФК2. Хроническая анемия смешанного генеза. Анемия, сопровождающая течение беременности, встречалась у 11 женщин, из них у 5 анемия 2-й степени. У одной женщины эпилепсия, дегенерация сетчатки в стадии ремиссии.

Таблица 2

Факторы риска, связанные с настоящей беременностью

\begin{tabular}{|c|c|c|c|c|c|c|c|c|c|c|}
\hline 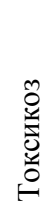 & 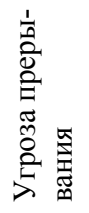 & 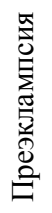 & & 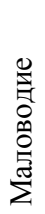 & $\vec{\nabla}$ & 当 & 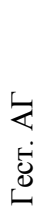 & $\begin{array}{l}\text { ન્ } \\
\dot{0} \\
0\end{array}$ & 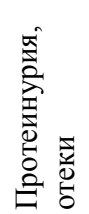 & 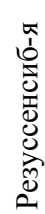 \\
\hline$n$ & $\simeq$ & 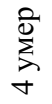 & $\begin{array}{l}\text { 总 } \\
\text { n }\end{array}$ & $N$ & $\infty$ & in & $\sigma$ & 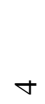 & $N$ & $\bar{\Xi}$ \\
\hline
\end{tabular}

Плодовые факторы: многоплодная беременность в 6 случаях, из них одна монохориальная диамниотическая двойня. Хромосомная аномалия встретилась в одном случае, женщина отказалась от ИПД, по УЗИ на втором скрининге: гиперплазия плаценты, гипоплазия спинки носа. Предлежание плаценты 1-й степени. На третьем скрининге выявлено: ЗВУР 1-й степени, ассиметричная форма.

Среди патологии плаценты встречалось предлежание плаценты 1-й степени в одном случае. Патология пуповины: ЕАП в двух случаях многоплодной беременности (СЗРП 1-й степени в обоих случаях).

Тактика ведения беременности: По литературным данным, если диагноз ЗРП выявляется во время беременности и проводится соответствующее обследование, наблюдение в динамике и своевременное родоразрешение, то риск развития у ребенка серьезных заболеваний и смерти снижается в 4-5 раз [4]. 
A. А. Елезова, Е. А. Ботоева. Сравнительный анализ причин задержки внутриутробного развития плода

К биохимическому маркеру 1-го триместра, свидетельствующему о нарушении формирования плаценты, изучаемом в контексте ЗРП, относится ассоциированный с беременностью протеин А (РАРР-А). Определение уровня РАРР-А проводится в нашей стране каждой беременной при прохождении скринингового исследования 1-го триместра. По рекомендациям Королевского колледжа акушеровгинекологов Великобритании, снижение РАРР-А $<0,415$ МоМ относится в «большим» факторам риска ЗРП. Также к первому скринингу относится измерение среднего АД и пульсационный индекс в маточных артериях.

По данным протокола «Нормальная беременность», биохимический скрининг 2-го триместра может быть назначен при отсутствии результатов скрининга 1-го триместра.

Из 31 у 6 женщин был пропущен первый скрининг по причине поздней явки или невыполнения женщиной рекомендаций. Из них три женщины не направлены участковыми акушерами-гинекологами на биохимический скрининг 2-го триместра (участки 6,7). Две женщины встали на учет во втором триместре и им не назначен биохимический скрининг 2-го триместра, у одной женщины по результатам первого скрининга выявлен высокий риск ЗРП (1:39), но после консультации перинатолога женщина не была направлена на дообследование. Две женщины были направлены, но не выполнили рекомендацию (участки 5, 8).

Две женщины получили удовлетворительные результаты ХГ, АФП и было проведено медико-генетическое консультирование (участки 8, 9). У одной их них выявлена хромосомная патология в ворсинах хориона по результатам дообследования и ЗВУР 1-й степени по УЗИ 3.

\section{Структура ЗВУР}

Таблицуа 3

\begin{tabular}{|l|r|l|r|r|r|}
\hline \multicolumn{2}{|l|}{ 3ВУР 1-й степени } & \multicolumn{2}{|c|}{ 3ВУР 2-й степени } & \multicolumn{2}{|c|}{ 3ВУР 3-й степени } \\
\hline 22 & 1 двойня & 4 & 2 двойни & 6 & 4 двойни \\
\hline
\end{tabular}

Выявляемость ЗВУР по акушерским участкам

Таблицุа 4

\begin{tabular}{|c|c|c|c|}
\hline Участок & 3ВУР 1-й степени & ЗВУР 2-й степени & ЗВУР 3-й степени \\
\hline 1 & 1 & 1 & \\
\hline 2 & 1 & & 1 \\
\hline 4 & 2 & & 1 \\
\hline 5 & 3 & & 1 (двойня) \\
\hline 6 & 2 & & \\
\hline 7 & 2 & & 2 (двойня) \\
\hline 8 & 2 & & 1 \\
\hline 9 & 1 & 1 (двойня) & \\
\hline 10 & 1 & 1 (двойня) & 1 \\
\hline 12 & 2 &
\end{tabular}


Количество беременностей, при которых во время беременности был выявлен ЗВУР плода - 17, из них при проведении УЗИ-12 по измерению ВДМ у 5 женщин. У 14 женщин ЗВУР не был выявлен во время беременности, три из которых были с многоплодной беременностью, три с ожирением (1 женщина до 20 недель наблюдалась, ЗВУР не был выявлен, с 20 недель наблюдение в РПЦ).

В диагностике ЗРП во время беременности важное значение имеет измерение ВДМ и ведение гравидограммы. Согласно протоколу, рекомендовано измерение ОЖ, ВДМ и ведение гравидограммы при каждом визите с 20-й недели. Если ВДМ согласно гравидограмме ниже 10-й или выше 90-й перцентили распределения ВДМ, то необходимо проведение УЗИ для оценки развития плода и определения количества околоплодных вод.

Рекомендовано направлять беременную пациентку группы высокого риска акушерских и перинатальных осложнений (ПЭ, ПР, ЗРП, предлежание плаценты) и в случае несоответствия ВДМ сроку беременности согласно гравидограмме на проведение УЗИ плода при сроке беременности 30-34 недели для диагностики поздноманифестирующих пороков развития плода, крупного или маловесного плода. (Уровень убедительности рекомендаций А.) Комментарии: Дополнительные УЗИ в 3-м триместре беременности (после 34-36 недель) могут быть назначены для уточнения при подозрении на неправильное положение или предлежание плода, при отсутствии или нарушении ЧСС плода (тахикардия, брадикардия, аритмия) во время аускультации ЧСС плода, при несоответствии размеров матки и срока беременности.

Международные эксперты высказывают мнение о том, что измерение ВДМ неэффективно при ожирении ИМТ более 35 , наличии больших миоматозных узлов, многоводии, многоплодии и при наполненном мочевом пузыре. А также этот метод лучше всего работает, когда все измерения проводятся одним и тем же лицом с использованием немаркированной ленты, с последующим составлением гравидограммы.

Среди 31 женщин имели построенную гравидограмму лишь 12. Оценка беременности по шкале перинатального риска была выполнена в 24 случаях из 31 . У 4 женщин врачи участков не обращали внимание на несоответствие ОЖ, ВДМ сроку беременности (участки $6,1,12$ ).

Согласно протоколу «Нормальная беременность», рекомендовано направлять беременную пациентку в 18-20-ю неделю беременности на проведение УЗИ плода (У3 скрининга 2-го триместра) для оценки роста плода, диагностики ранних форм ЗРП, исключения врожденных аномалий развития, оценки экстраэмбриональных структур (локализации, толщины, структуры плаценты, количества околоплодных вод) и УЗИ шейки матки (УЗ-цервикометрию) в медицинскую организацию, осуществляющую пренатальную диагностику.

Комментарий. Дополнительные УЗИ во 2-м триместре беременности могут быть назначены при отсутствии или нарушении ЧСС плода (тахикардия, брадикардия, аритмия) во время аускультации ЧСС плода.

Рекомендовано направлять беременную пациентку группы высокого риска акушерских и перинатальных осложнений (ПЭ, ПР, ЗРП) на проведение ультразвуковой допплерографии маточно-плацентарного кровотока во время 2-го УЗИ (при сроке беременности 18-20 недель), и в 3-м триместре беременности (при сроке беременности 30-34 недели). 
A. А. Елезова, Е. А. Ботоева. Сравнительный анализ причин задержки внутриутробного развития плода

Согласно международным рекомендациям, у женщин с ФР ЗРП допплеровский скрининг маточной артерии в сроки от 19-23 недель может идентифицировать беременность с риском мертворождения и ЗРП. Необходимо проводить допплерометрию маточной артерии у женщин высокого риска: в 20 недель, если > 3 ФР.

При анализе было выявлено отсутствие контрольного УЗИ, допплерометрии в соответствующие сроки и при имеющихся нарушениях у 5 женщин (участки 1, 5, 2,11 - нерегулярные явки). Неполное обследование, включающее отсутствие консультации терапевта чаще всего в 30 недель, было выявлено у 12 женщин. Лабораторное обследование было проведено у всех женщин в полном объеме, за исключением исследования уровня ферритина, сывороточного железа при анемии, исследование уровня ТТГ. Данное обследование отсутствовало в большинстве карт.

Данные факты свидетельствуют о неполном обследовании беременных женщин в соответствии с нормативными документами и, как следствие, об отсутствии прогнозирования риска возникновения ЗРП. Нерегулярные явки, отсутствие выполнения рекомендаций врача, отказы от госпитализаций были выявлены у 9 женщин. У двух из них было менее 5 явок и зафиксированы патронажи на дому.

Стационарное лечение. Самое многочисленное число госпитализаций было по поводу угрозы прерывания беременности (10 женщин), одна госпитализация с токсикозом - рвота беременных средней степени тяжести.

С декомпенсацией экстрагенитальной патологии связаны 8 случаев госпитализации, основная доля связана с гестационной артериальной гипертензией.

С ФПН госпитализировали женщин в 7 случаях, одну женщину со ЗВУР 2-й степени НМПК 1 Б. Две женщины с ФПН прошли лечение в дневном стационаре, включающее раствор актовегина в/в, что не имеет доказательной базы в лечении ФПН. При распределении частоты выявляемости ЗВУР по акушерско-гинекологическим участкам было выявлено, что чаще всего ЗВУР диагностировано на участках 5, 6, 8, 4, 11, 12.

\begin{tabular}{|l|l|l|l|l|l|l|l|l|l|l|l|l|}
\hline $\begin{array}{l}\text { Уча- } \\
\text { сток }\end{array}$ & $\mathbf{1}$ & $\mathbf{2}$ & $\mathbf{3}$ & $\mathbf{4}$ & $\mathbf{5}$ & $\mathbf{6}$ & $\mathbf{7}$ & $\mathbf{8}$ & $\mathbf{9}$ & $\mathbf{1 0}$ & $\mathbf{1 1}$ & $\mathbf{1 2}$ \\
\hline $\begin{array}{l}\text { Ко- } \\
\text { личе- } \\
\text { ство } \\
\text { слу- } \\
\text { чаев } \\
\text { ЗВУР }\end{array}$ & 2 & 1 & 0 & 3 & 4 & 4 & 2 & 3 & 2 & 1 & 3 & 3 \\
\hline
\end{tabular}

В структуре исходов беременности превалируют своевременные роды -20 , частота преждевременных - 11, 3 из которых многоплодная беременность.

Стоит отметить отсутствие соблюдение врачами ЖК следующих рекомендаций в соответствии с протоколом «Нормальная беременность». Например, беременной пациентке группы высокого риска гиповитаминоза витамина D рекомендовано назначить пероральный прием витамина D на протяжении всей беременности в дозе 10 мкг (400 MЕ) в день. (Уровень убедительности рекомендаций В) 
Комментарии: В группе высокого риска гиповитаминоза витамина D его назначение снижает риск таких акушерских осложнений, как ПЭ, ЗРП и ГСД.

K группе высокого риска гиповитаминоза витамина D относятся женщины с темной кожей, имеющие ограничения пребывания на солнце, со сниженным уровнем потребления мяса, жирной рыбы, яиц, с ИМТ до беременности $\geq 30$ кг/м. Беременной пациентке группы низкого риска гиповитаминоза витамина D не рекомендовано назначать прием витамина D. Ни в одном случае ЗРП не было назначено при наличии факторов риска возникновения ЗРП профилактических доз витамина Д.

Курящей беременной пациентке может быть рекомендован прием Омега-3 полиненасыщенных жирных кислот, так как это снижает риск спонтанных ПР и рождения маловесных детей. Ни в одном случае ЗРП не было назначено при наличии вредных привычек Омега-3 полиненасыщенных жирных кислот.

Беременной пациентке должны быть даны рекомендации по отказу от курения, отказу от алкоголя. Курение во время беременности ассоциировано с такими осложнениями, как ЗРП, ПР, предлежание плаценты, преждевременная отслойка нормально расположенной плаценты (ПОНРП), гипотиреоз у матери, преждевременное излитие околоплодных вод, низкая масса тела при рождении, перинатальная смертность и эктопическая беременность. Примерно 5-8\% ПР, 13-19\% родов в срок ребенком с низкой массой тела, 23-34\% случаев внезапной детской смерти и 5-7\% смертей в детском возрасте по причинам, связанным с патологическим течением пренатального периода, могут быть ассоциированы с курением матери во время беременности. Ни в одном случае ЗРП не было назначено при наличии вредных привычек Омега-3 полиненасыщенных жирных кислот.

Международные эксперты рекомендуют проводить оценку риска при постановке на учет прежде всего ПЭ, ЗРП в анамнезе, курение, ожирение. После оценки следует проводить беседу с женщиной и брать подпись у женщины о информированности об исключении ФР.

Таким образом, выявлена основная задача врача ЖК: оценить факторы риска, направить все имеющиеся ресурсы для модификации факторов риска, а также построить план ведения беременности в зависимости от риска возникновения БАС и как следствие ЗРП.

В соответствии с данными рекомендациями выявлены следующие дефекты оказания помощи:

1. При постановке на учет происходит недостаточно полноценный сбор анамнеза, идентификация имеющихся факторов риска у пациентки, не рассчитывается ИМТ. В соответствии с этим не назначаются профилактические дозы витаминов. Рекомендации из протокола Нормальная беременность 2020 г., касающиеся приема витамина Д, омега 3 , отказа от курения, отсутствовали во всех случаях.

2. Не рассчитывается перинатальный риск, ведение беременной происходит не в соответствии с группой повышенного риска ЗРП и других акушерских осложнений.

3. При беременности в некоторых случаях отсутствует ведение гравидограммы, мониторинг прироста ВДМ, ОЖ.

4. Зачастую причиной отсутствия полного спектра обследования беременной женщины являются нерегулярные явки и невыполнение женщиной рекомендаций врача. 
A. А. Елезова, Е. А. Ботоева. Сравнительный анализ причин задержки внутриутробного развития плода

5. В некоторых случаях ведение беременности происходит без участия врачей смежных специальностей, а именно врача-терапевта, гематолога, кардиолога. Это, в свою очередь, ведет к неполноценной коррекции имеющейся экстрагенитальной патологии.

Выводы:

В данной работе была предпринята попытка оценить этиологию ЗРП, выделив рекомендуемые в литературе основные группы факторов риска.

Первая группа социально-биологические ФР. Выявлено, что в 9,6\% случаев отмечалось рождение детей со ЗВУР от возрастных первородящих. При учете профессии и профессиональных вредностей выявлено, что большинство женщин $(77,4 \%)$ были неработающими (домохозяйками), в подавляющем большинстве случаев имеющими низкий материальный уровень в семье, 22,5\% беременных были учащимися и студентками, у которых психологические и физические нагрузки, а также недостаточное и несбалансированное питание оказали неблагоприятное воздействие на развитие плода. $32,2 \%$ беременных имели низкую массу тела. Большинство $(45,1 \%)$ были первородящими женщинами. Вредные привычки имели $45,1 \%$ женщин.

Вторая группа факторов риска: материнские факторы, среди сопутствующих заболеваний матери отмечалась ГБ в 9,6\% случаев, ОРВИ, включая НКИ в 16,1\%, заболевания щитовидной железы $(6,4 \%)$, инфекционные заболевания $(6,4 \%)$, а также декомпенсированный СД 1 типа и СКВ. Анемия осложняла течение беременности в $35,4 \%$ случаев.

Ведущее место среди патологии беременности занимает угроза прерывания беременности $(38,7 \%)$, преэклампсия (29\%), хроническая фетоплацентарная недостаточность $(25,8 \%)$. Далее следуют гестационная артериальная гипертензия и гестационный сахарный диабет по 12,9\%. На долю токсикозов пришлось 9,6\%.

Третья группа факторов - плацентарные факторы риска. Сюда относятся аномалии прикрепления плаценты - один случай, ЕАП - два случая. Перечисленные структурные аномалии плаценты и пуповины приводили к уменьшению площади поверхности, участвующей в обмене веществ между матерью и плодом.

Четвертая группа факторов риска - плодовые факторы. При анализе процент многоплодной беременности составил 19,3\%, один случай хромосомной аномалии.

Таким образом, согласно проведенному исследованию, наиболее частыми факторами риска рождения детей с ЗРП являются следующие:

1) патология беременности (хроническая фетоплацентарная недостаточность, угроза прерывания беременности, преэклампсия;

2) соматические и инфекционные заболевания матери как до беременности, так и во время нее (сердечно-сосудистая патология, заболевания щитовидной железы, ОРВИ, СД;

3) несбалансированное и нерациональное питание беременных женщин, что связано с неблагоприятной социально-экономической обстановкой в семье.

Внедрение в ежедневную клиническую практику современных алгоритмов прогнозирования, методов эффективной профилактики, унифицированных критериев диагностики и принципов ведения случаев ЗРП, базирующихся на результа- 
тах исследований с высоким уровнем достоверности доказательств, будет являться базой для значительного снижения уровня перинатальной заболеваемости и смертности.

В частности, в условиях ЖК важно обратить внимание на следующие моменты:

1) проводить профилактическую работу по поводу предгравидарной подготовки женщин репродуктивного возраста;

2) при постановке на учет тщательно осуществлять сбор анамнеза, определять группу риска и наблюдать течение беременности в соответствии с выделенной группой перинатального риска;

3) предпринимать возможные попытки по модификации и устранению имеющихся факторов риска, скорректировать алгоритм направления на УЗ-исследование состояния плода;

4) следить за приростом массы тела, ВДМ, ОЖ, шевелениями плода у женщин. Ввести обязательное ведение гравидограммы.

\section{Литература}

1. Ярыгина Т. А., Гус А. И. Задержка (замедление) роста плода: все, что необходимо знать практикующему врачу // Акушерство и гинекология. 2020. 12. 14-24. Текст: непосредственный.

2. К вопросу о возможности использования козьего молока и адаптированных смесей на его основе в детском питании / Т. Э. Боровик, Н. Н. Семенова, О. Л. Лукоянова и др. // Вопросы современной педиатрии. 2013. № 12(1). С. 8-10. Текст: непосредственный.

3. Early childhood neurodevelopment after intrauterine growth restriction: a systematic review / T. A. Levine, R. E. Grunau, F. M. McAuliffe [et al.] // Pediatrics. 2015. Vol. 135, no. 1. P. 26-141.

4. Tidjani Alou M., Lagier J. C., Raoult D. Diet influence on the gut microbiota and dysbiosis related to nutritional disorders // Human Microbiome Journal. 2016. No. 1. P. 3-11.

5. Нетребенко О. К. Метаболическое программирование в антенатальном периоде // Вопросы гинекологии, акушерства и перинатологии. 2012. № 11(6). С. 58-64. Текст: непосредственный.

6. Щеплягина Л. В., Нетребенко О. К. Питание беременной женщины и программирование заболеваний ребенка на разных этапах онтогенеза (теоретические и практические вопросы) // Лечение и профилактика. 2012. № 1(2). С. 7-15. Текст: непосредственный.

7. Подходы по оптимизации питания и физического развития у недоношенных новорожденных на втором этапе выхаживания / О. В. Халецкая, М. А. Суслова, Е. Е. Яцышина, Н. А. Федорина // Медицинский альманах. 2018. № 3(54). С. 42-44. Текст: непосредственный.

8. Радзинский В. Е. Акушерская агрессия. № 2.0. Москва: StatusPraesens, 2017. 870 с. Текст: непосредственный.

9. Платовская Д. В. Дети с задержкой внутриутробного развития: ранняя гормональная адаптация и клинико-психологические особенности: автореферат диссертации на соискание ученой степени кандидата медицинских наук. Воронеж, 2011. 24 с. Текст: непосредственный.

Статья поступила в редакиию 09.10.2021; одобрена после рецензирования 25.11.2021; принята к публикации 22.12.2021. 


\section{OF INTRAUTERINE GROWTH RETARDATION}

Anna A. Elezova

Medical Resident,

Dorzhi Banzarov Buryat State University

36a Oktyabrskaya St., Ulan-Ude 670000, Russia

elenabotoeva@list.ru

\section{Elena A. Botoeva}

Cand. Sci. (Medecine), A/Prof.,

Dorzhi Banzarov Buryat State University

36a Oktyabrskaya St., Ulan-Ude 670000, Russia

elenabotoeva@list.ru

Abstract. Disorders in the fetal development period cause a large proportion of stillbirths, as well as affect the level of neonatal and child mortality, and lead to long-term negative consequences for the subsequent growth, development and health of children. According to WHO experts, among the remote consequences of inadequate nutrition in the early stages of child development, there is an increased risk of disease and death by them in any period of life. In this regard, the category of children with low birth weight by gestational age deserves special attention from neonatologists, pediatricians, and nutritionists.

Delayed fetal growth can lead to a whole spectrum of perinatal complications, including intrauterine fetal demise, asphyxia, amniotic fluid aspiration, and increased frequency of caesarean operations.

The introduction of modern prediction algorithms, effective prevention methods, unified diagnostic criteria and principles for managing intrauterine growth restriction cases, based on the results of studies with a high level of reliability of evidence, into daily clinical practice will be the basis for a significant reduction in the level of perinatal morbidity and mortality. Fetal growth delay is responsible for every third case of antenatal death.

In this work, we have made an attempt to assess the etiology of intrauterine growth restriction by identifying the main risk factors described in the modern literature.

Keywords: intrauterine growth retardation, perinatal complications, intrauterine fetal demise.

\section{For citation}

Elezova A. A., Botoeva E. A. Comparative Analysis of the Causes of Intrauterine Growth Retardation. Bulletin of Buryat State University. Medicine and Pharmacy. 2021; 2: 29-39 (In Russ.).

The article was submitted 29.10.2021; approved after reviewing 25.11.2021; accepted for publication 22.12.2021. 